\author{
Omnia E Hussein', Mousa O \\ Germoush $^{2}$ and Ayman M Mahmoud ${ }^{*}$ \\ ${ }^{1}$ Physiology Division, Zoology Department, Faculty of \\ Science, Beni-Suef University, Beni-Suef, Egypt \\ ${ }^{2}$ Department of Biology, Faculty of Science, Aljouf \\ University, Sakaka, Saudi Arabia \\ Dates: Received: 22 December, 2015; Accepted: \\ 20 February, 2016; Published: 22 February, 2016 \\ *Corresponding author: Ayman M. Mahmoud, PhD \\ Physiology Division, Zoology Department, Faculty \\ of Science, Beni-Suef University, Salah Salim St, \\ 62514, Beni-Suef, Egypt. Tel.: +201144168280; \\ E-mail: aymano911@yahoo.com; ayman.mahmoud@ \\ science.bsu.edu.eg \\ www.peertechz.com
}

Keywords: Renal injury; Rue; Oxidative stress; Inflammation; Anti-tuberculosis therapy
Research Article

\section{Ruta graveolens Protects Against Isoniazid/Rifampicin-Induced Nephrotoxicity Through Modulation of Oxidative Stress and Inflammation}

\section{Introduction}

The kidney is a vital organ required to essential functions including regulation of the extracellular environment, maintenance of homeostasis, and detoxification and excretion of drugs and toxic metabolites [1]. The kidneys are therefore vulnerable to drug-induced toxicity. Drug-induced nephrotoxicity is a renal dyfunction that arises as a direct or indirect result of exposure to drugs [2]. Nephrotoxic drugs are therapeutic agents that have the potential to induce adverse effects on renal function due to direct toxicity or compromised renal perfusion [3]. Previous studies showed that nephrotoxic drugs were responsible for $19 \%-25 \%$ of acute kidney injury in critically ill patients [4-6]. Nephrotoxic drug-induced kidney dysfunction include acute tubular necrosis, haemodynamically mediated damage, glomerular and tubulointerstitial injury and obstructive nephropathy [7].

The use of anti-tuberculosis drugs, isoniazid and rifampicin, has been reported to be associated with hepatotoxicity that could result in acute liver injury and a high mortality rate $[8,9]$. The rate of their hepatotoxic effects is much higher in developing countries than that in developed countries [10]. We have demonstrated the contribution of oxidative stress and inflammation in isoniazid-induced hepatotoxicity [9]. In addition, studies have reported that reactive oxygen species and oxidative stress play a key role in the pathogenesis of drug-induced renal damage $[11,12]$. Although hepatotoxicity of the anti-tuberculosis drugs has been extensively studied, their induced nephrotoxicity has been poorly documented. Recently, we reported that isoniazid and rifampicin combination induced nephrotoxicity associated with oxidative stress and inflammation in rats [13].

Medicinal plants are broadly used in the treatment of several diseases owing their cheapness, safety and nontoxicity when compared with the synthetic drugs [14]. Ruta graveolens L. (Family: Rutaceae) is an ancient medicinal plant. It is commonly known as rue or sadab and currently used for treatment of eye problems, dermatitis, aching pain, rheumatism, psoriasis, multiple sclerosis, leucoderma and cutaneous lymphomas [15]. Multiple studies have reported that rue possesses hepatoprotective, anticancer, anti-inflammatory, antioxidant, antihyperammonemic and antidiabetic activities [16-19]. Recently, we demonstrated the protective effect of $R$. graveolens leaves extract against diethylnitrosamine-induced kidney damage in rats [20]. Although the beneficial effects of $R$. graveolens in multiple disease cases have been reported, its protective effect against nephrotoxicity associated with the use of anti-tuberculosis drugs has not been studied. Therefore, the present study was designed to scrutinize the protective effects of $R$. graveolens leaves extract against isoniazid/ rifampicin-induced renal injury in rats, focusing on oxidative stress and inflammation. 


\section{Materials and Methods}

\section{Chemicals}

Isoniazid (INH) was supplied by El Nasr Company for Chemicals and Drugs (Cairo, Egypt), and rifampicin (RIF) was purchased from Novartis Pharma Company (Cairo, Egypt). Reduced glutathione (GSH), pyrogallol, trichloroacetic acid (TCA), thiobarbituric acid (TBA) and 5,5'-dithiobis-(2-nitrobenzoic acid) (DTNB) were purchased from Sigma (USA). All other chemicals were of analytical grade and obtained from standard commercial supplies.

\section{Collection of plant and extract preparation}

R. graveolens (sadab) was collected and the extract was prepared as we reported previously [19]. Briefly, sadab was obtained from the Experimental Station of Medical Plants (ESMP), Faculty of Pharmacy, Cairo University (Egypt). The plant leaves were collected, cleaned, air dried and ground with an electric grinder. The powdered leaves were macerated in $80 \%$ aqueous ethanol for $24 \mathrm{~h}$ at room temperature. Following filtration, the filtrate was concentrated under vacuum in a rotary evaporator. The residue obtained was stored frozen till use.

\section{Animals and treatments}

Male Wistar rats weighing 140-160 g, obtained from animal house of the National Research Centre (El-Giza, Egypt) were included in the present investigation. The animals were housed in plastic well-aerated cages ( 6 rats/cage) at normal atmospheric temperature $\left(25 \pm 2^{\circ} \mathrm{C}\right)$ and normal $12 \mathrm{~h}$ light/dark cycle. Rats had free access to water and were supplied daily with laboratory standard diet of known composition ad libitum. All animal procedures were undertaken with the approval of Institutional Animal Ethics Committee of Beni-Suef University (Egypt).

Twenty-four rats were divided to four groups $(\mathrm{N}=6)$ and were subjected to the following treatments:

Group I (Control): Rats received the vehicle $0.5 \%$ carboxymethylcellulose (CMC) via oral gavage for 45 days and served as control.

Group II (INH/RIF): Rats received isoniazid (50 mg/kg body weight), rifampicin (50 mg/kg body weight) and $0.5 \%$ CMC orally for 45 days [13].

Group III (INH/RIF + $50 \mathrm{mg}$ R. graveolens): Rats received isoniazid $(50 \mathrm{mg} / \mathrm{kg})$, rifampicin $(50 \mathrm{mg} / \mathrm{kg})$ and $50 \mathrm{mg} / \mathrm{kg}$ body weight $R$. graveolens leaves extract dissolved in $0.5 \% \mathrm{CMC}$ orally for 45 days [20].

Group IV (INH/RIF + $100 \mathrm{mg}$ R. graveolens): Rats received isoniazid $(50 \mathrm{mg} / \mathrm{kg})$ and rifampicin $(50 \mathrm{mg} / \mathrm{kg})$ dissolved in water and $100 \mathrm{mg} / \mathrm{kg}$ body weight $R$. graveolens leaves extract dissolved in $0.5 \%$ CMC orally for 45 days [19].

The doses of INH, RIF and $R$. graveolens were balanced consistently over the entire period of study, as indicated by any change in body weight.

\section{Samples preparation}

By the end of the experiment, rats were sacrificed under ether anesthesia and blood samples were collected, left to coagulate and centrifuged at $3000 \mathrm{rpm}$ for $15 \mathrm{~min}$ to separate serum. Kidneys were immediately excised, perfused with ice-cold saline, and samples were kept frozen or fixed in $10 \%$ buffered formalin for histological processing. Frozen samples $(10 \% \mathrm{w} / \mathrm{v})$ were homogenized in chilled phosphate buffered saline and the homogenates were centrifuged at $3000 \mathrm{rpm}$ for $10 \mathrm{~min}$. The clear homogenates were collected and used for assaying oxidative stress and antioxidant defenses.

\section{Biochemical assays}

Determination of serum creatinine, urea and uric acid: Serum creatinine, urea and uric acid levels were assayed using reagent kits purchased from Biosystems (Spain), following the methods of Young [21], Kaplan [22] and Fossati et al. [23], respectively.

Determination of tumor necrosis factor-alpha (TNF- $\alpha$ ): Serum levels of TNF- $\alpha$ were determined by specific ELISA kits purchased from R\&D Systems (USA), according to the manufacturer's instructions. The concentration of TNF- $\alpha$ was determined spectrophotometrically at $450 \mathrm{~nm}$. Standard plot was constructed by using standard cytokine and the concentration for unknown samples was calculated from the standard plot.

Determination of oxidative stress and antioxidant defenses: Lipid peroxidation, assayed as malondialdehyde (MDA), was determined in kidney homogenate according to the method of Preuss et al. [24]. Nitric oxide level was estimated in the kidney homogenate as nitrite according to the method of Montgomery and Dymock [25], using reagent kit purchased from Biodiagnostics (Egypt). The assay is based on the Griess method which is a simple colorimetric reaction between nitrite, $\mathrm{N}$-(1-naphthyl) ethylenediamine and sulfonamide to produce a pink product with maximum absorbance at $543 \mathrm{~nm}$. Reduced glutathione (GSH) content was assayed according to the method of Beutler et al. [26]. Glutathione peroxidase (GPx) and superoxide dismutase (SOD) activities were measured according to the methods of Matkovics et al. [27] and Marklund and Marklund [28], respectively.

\section{Histopathological study}

Kidney samples were flushed with cold saline and then fixed in $10 \%$ buffered formalin for at least $24 \mathrm{~h}$. The specimens were then dehydrated in ascending series of ethanol, cleared in xylene and embedded in paraffin wax. Blocks were prepared and $4 \mu \mathrm{m}$ thick sections were cut by a sledge microtome. The paraffin embedded sections were deparaffinized, washed and stained with hematoxylin and eosin $(\mathrm{H} \& \mathrm{E})$. The stained slides were examined under light microscope.

\section{Statistical analysis}

Statistical analysis was performed using GraphPad Prism 5 software (GraphPad Software, San Diego, CA, USA). Results were expressed as mean \pm standard deviation (SD) and all statistical comparisons were made by means of the one-way ANOVA test followed by Tukey's test post hoc analysis. A P value $<0.05$ was considered significant. 
Table 1: Serum creatinine, urea and uric acid levels in control, INH/RIF and INH/ RIF rats treated with Ruta graveolens.

\begin{tabular}{|c|c|c|c|}
\hline & $\begin{array}{c}\text { Creatinine }(\mathrm{mg} / \\
\mathrm{dl})\end{array}$ & Urea (mg/dl) & $\begin{array}{c}\text { Uric acid (mg/ } \\
\text { dl) }\end{array}$ \\
\hline Control & $0.87 \pm 0.04$ & $23.90 \pm 3.78$ & $1.54 \pm 0.30$ \\
\hline INH/RIF & $1.56 \pm 0.22^{* \star *}$ & $65.93 \pm 2.59^{* * *}$ & $4.21 \pm 0.99^{* * *}$ \\
\hline $\begin{array}{l}\mathrm{INH} / \mathrm{RIF}+50 \mathrm{mg} \\
R . \text { graveolens }\end{array}$ & $0.93 \pm 0.13^{\# \# \#}$ & $30.21 \pm 2.72^{\ldots \#}$ & $2.15 \pm 0.61 \#$ \\
\hline $\begin{array}{l}\mathrm{INH} / \mathrm{RIF}+100 \mathrm{mg} \\
R . \text { graveolens }\end{array}$ & $0.90 \pm 0.13^{\# \# \#}$ & $31.34 \pm 4.12^{\# \# \#}$ & $1.63 \pm 0.22^{\# \#}$ \\
\hline \multicolumn{4}{|c|}{$\begin{array}{l}\text { Data are expressed as } \mathrm{M} \pm \mathrm{SD} .{ }^{* * *} \mathrm{P}<0.001 \text { vs control, and \#\#P<0.01 and } \\
\# \# \#<0.001 \text { vs INH/RIF. INH, isoniazid; RIF, rifampicin; } R \text {. graveolens, Ruta } \\
\text { graveolens; } \mathrm{SD} \text {, standard deviation; vs, versus. }\end{array}$} \\
\hline
\end{tabular}

\section{Results}

Data summarized in Table 1 show the effect of isoniazid/ rifampicin administration and treatment with $R$. graveolens leaves extract on renal function markers. The administration of isoniazid/ rifampicin produced marked impairment of kidney function as showed by the significant $(\mathrm{P}<0.001)$ increase in serum creatinine, urea and uric acid levels. Concurrent oral administration of $50 \mathrm{mg} / \mathrm{kg}$ $R$. graveolens leaves extract significantly decreased the elevated levels of serum creatinine $(\mathrm{P}<0.001)$, urea $(\mathrm{P}<0.001)$ and uric acid $(\mathrm{P}<0.01)$ when compared with the isoniazid/rifampicin control group. Similarly, administration of $100 \mathrm{mg} / \mathrm{kg}$ R. graveolens significantly $(\mathrm{P}<0.001)$ alleviated serum levels of creatinine, urea and uric acid in isoniazid/rifampicin-induced rats.

Serum levels of TNF- $\alpha$ exhibited a significant $(\mathrm{P}<0.001)$ increase in isoniazid/rifampicin-intoxicated rats when compared with the control group, as depicted in Figure 1. Although non-significant ( $\mathrm{P}>0.05)$, concomitant supplementation of the $50 \mathrm{mg} / \mathrm{kg} R$. graveolens leaves extract decreased serum TNF- $\alpha$. On the other hand, administration of the higher $R$. graveolens dose $(100 \mathrm{mg} / \mathrm{kg})$ produced a significant $(\mathrm{P}<0.001)$ decrease in circulating levels of TNF- $\alpha$ when compared with the isoniazid/rifampicin-administered rats.

Histopatholgical examination of the kidney sections of control rats showed normal histological structure of the renal tissue (Figure 2A). Conversely, isoniazid/rifampicin-induced rats showed several histopathological changes and lesions, including atrophy of glomerular tuft, dysplastic renal tubules and inflammatory cells infiltration (Figure 2B). Concurrent treatment of the isoniazid/ rifampicin-administered rats with either 50 or $100 \mathrm{mg} / \mathrm{kg} R$. graveolens leaves extract produced marked improvement in the kidney histological structure and prevented the isoniazid/rifampicininduced alterations, as represented in Figure 2C and 2D, respectively.

Concerning lipid peroxidation, rats received isoniazid/rifampicin orally for 45 days exhibited significantly $(\mathrm{P}<0.001)$ increased renal lipid peroxidation levels when compared with the normal control rats, as represented in Figure 3. Concurrent oral administration of R. graveolens at dose levels of both 50 and $100 \mathrm{mg} / \mathrm{kg}$ produced a significant $(\mathrm{P}<0.001)$ amelioration in the lipid peroxidation marker, MDA, in isoniazid/rifampicin-induced rats.

Renal nitric oxide exhibited a similar pattern. It showed a significant $(\mathrm{P}<0.001)$ increase in kidney of isoniazid/rifampicinadministered rats. Oral administration of either 50 or $100 \mathrm{mg} / \mathrm{kg} R$. graveolens leaves extract markedly $(\mathrm{P}<0.05)$ decreased renal nitric oxide levels in isoniazid/rifampicin-induced rats, as depicted in Figure 4.

On the contrary, 45 days of isoniazid/rifampicin administration significantly $(\mathrm{P}<0.001)$ decreased kidney GSH content when compared with the control group (Figure 5). Concurrent supplementation of either 50 or $100 \mathrm{mg} / \mathrm{kg}$ R. graveolens leaves extract produced a significant $(\mathrm{P}<0.001)$ alleviation of renal GSH content. Similarly, GPx activity showed a significant $(\mathrm{P}<0.001)$ decrease in the kidney of isoniazid/rifampicin-induced rats, as represented in Figure 6. SOD activity as well was significantly $(\mathrm{P}<0.001)$ decreased in the kidney of isoniazid/rifampicin-induced rats when compared with the control group (Figure 7). Oral supplementation of $50 \mathrm{mg} / \mathrm{kg}$ R. graveolens leaves extract potentially $(\mathrm{P}<0.01)$ ameliorated the activity of $\mathrm{GPx}$ and SOD in kidney of isoniazid/rifampicin-intoxicated rats. At the higher dose $(100 \mathrm{mg} / \mathrm{kg}), R$. graveolens leaves extract significantly enhanced the activity of GPx $(\mathrm{P}<0.001)$ and SOD $(\mathrm{P}<0.01)$ in kidney of isoniazid/rifampicin-induced rats.

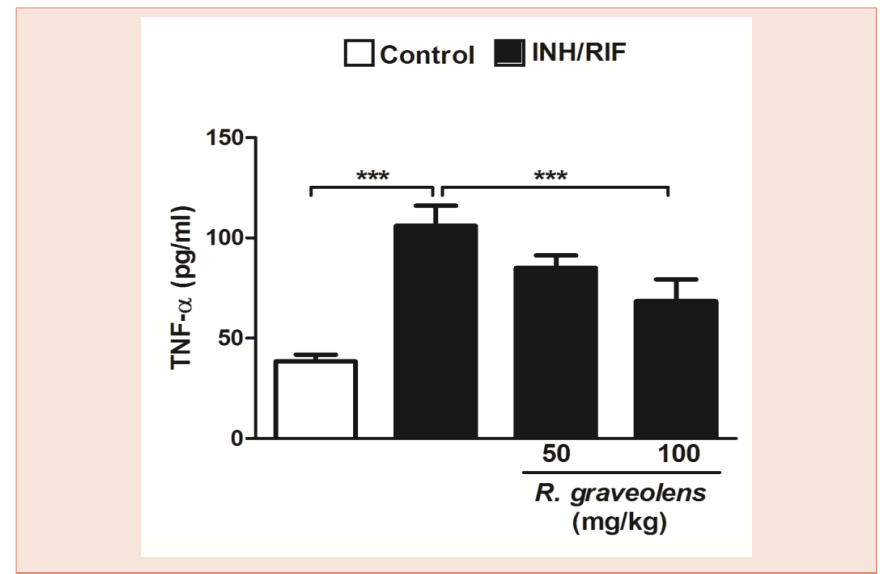

Figure 1: Serum TNF- $\alpha$ levels in control, INH/RIF and INH/RIF rats treated with Ruta graveolens. Data are expressed as $\mathrm{M} \pm \mathrm{SD}$. ${ }^{* *} \mathrm{P}<0.001$. INH, isoniazid; RIF, rifampicin; TNF- $\alpha$, tumor necrosis factor alpha; SD, standard deviation.

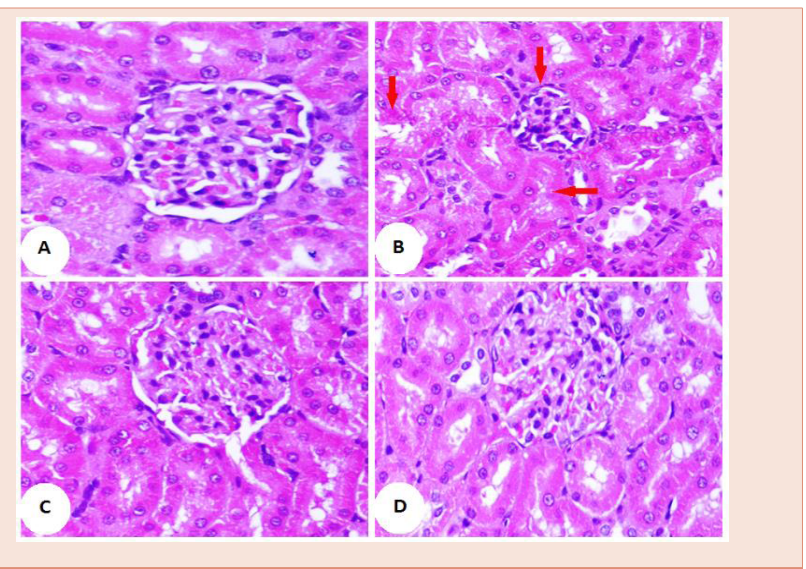

Figure 2: Photomicrographs of H\&E stained kidney sections of control (A [x400]) showing normal histological structure, INH/RIF (B [x400]) showing dysplastic renal tubules, and atrophy of glomerular tuft, INH/RIF + 50 mg Ruta graveolens (C [x400]), and INH/RIF + $100 \mathrm{mg}$ Ruta graveolens (D [x400]) showing nearly normal renal tubules and renal corpuscles. 


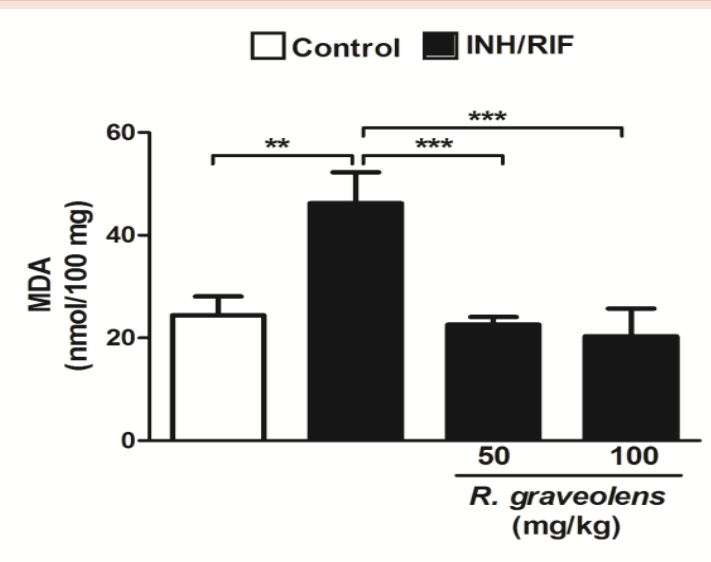

Figure 3: Lipid peroxidation levels in kidneys of control, INH/RIF and INH/RIF rats treated with Ruta graveolens. Data are expressed as $M \pm S D$. ${ }^{* *} P<0.01$ and ${ }^{* * *} \mathrm{P}<0.001$. INH, isoniazid; RIF, rifampicin; MDA, malondialdehyde; SD, standard deviation.

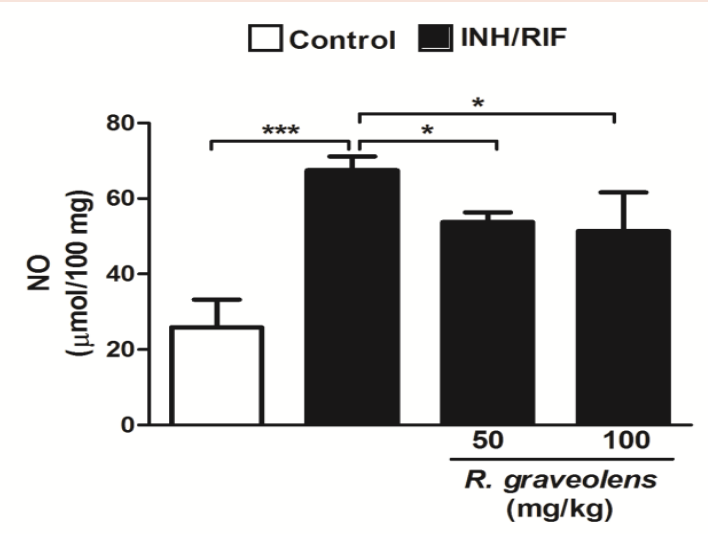

Figure 4: Nitric oxide levels in kidneys of control, INH/RIF and INH/RIF rats treated with Ruta graveolens. Data are expressed as $M \pm S D$. ${ }^{*} P<0.05$ and ${ }^{* * *} \mathrm{P}<0.001$. INH, isoniazid; RIF, rifampicin; $\mathrm{NO}$, nitric oxide; SD, standard deviation.

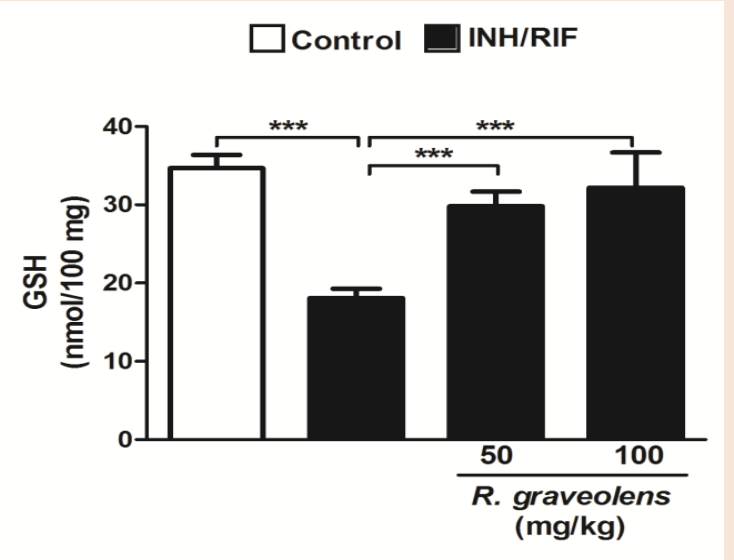

Figure 5: Reduced glutathione in kidneys of control, INH/RIF and INH/RIF rats treated with Ruta graveolens. Data are expressed as $\mathrm{M} \pm \mathrm{SD}$. ${ }^{* * *} \mathrm{P}<0.001$. INH, isoniazid; RIF, rifampicin; GSH, glutathione; SD, standard deviation.

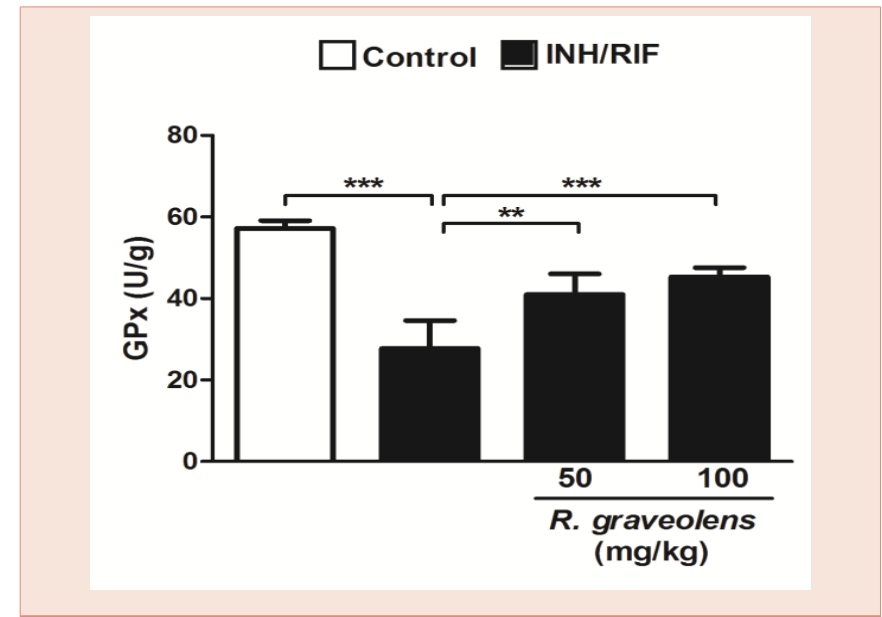

Figure 6: Glutathione peroxidase activity in kidneys of control, INH/RIF and INH/RIF rats treated with Ruta graveolens. Data are expressed as $\mathrm{M} \pm \mathrm{SD}$. ${ }^{* * *} \mathrm{P}<0.001$. INH, isoniazid; RIF, rifampicin; GPx, glutathione peroxidase; SD, standard deviation.

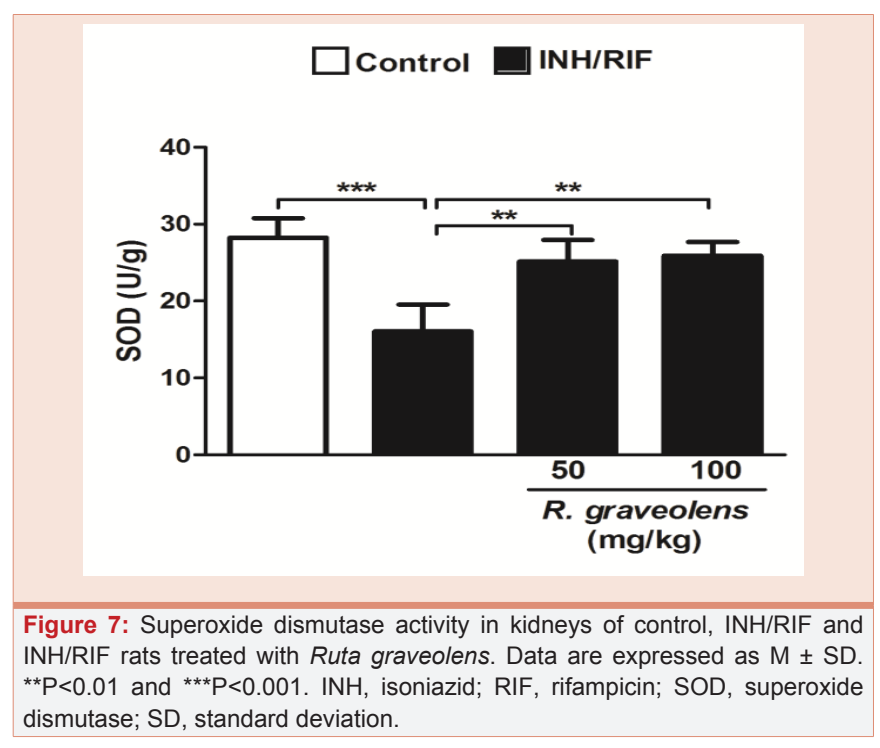

\section{Discussion}

In this investigation, we evaluated the protective effects of $R$. graveolens leaves extract on isoniazid/rifampicin-induced nephrotoxicity in rats. We found for the first time that concurrent treatment with $R$. graveolens protected against kidney injury through attenuation of inflammation and oxidative stress, and potentiating the antioxidant defenses.

Nephrotoxicity and nephropathy are important microvascular complication of anti-tuberculosis therapy $[9,13,29]$. Multiple studies have demonstrated that both inflammation and oxidative stress are implicated in drug-induced organ injury [9,13,30]. Rekha et al. [29], reported that anti-tuberculosis therapy-induced renal injury is usually reversible and could be treated properly if detected early. In this context, Mahmoud et al. [13], suggested that the use of antioxidants could protect against isoniazid/rifampicin-induced oxidative stress and nephrotoxicity. Therefore, we have attempted to test the 
hypothesis that $R$. graveolens leaves extract could protect against isoniazid/rifampicin-induced renal damage through attenuation of inflammation and prevention of oxidative stress.

The present findings showed that administration of isoniazid and rifampicin has induced kidney injury and glomerular dysfunction evidenced by the elevated circulating creatinine, urea and uric acid levels. These measurements are often regarded as reliable markers of kidney damage [31] and indicate the loss of a majority of kidney function [32]. These elevated assessments are in agreement with the studies of Hashmi et al. [33], who reported increased serum levels of creatinine and urea in albino rabbits following administration of antituberculosis drugs. More recently, we demonstrated elevated serum creatinine, urea and uric acid in serum of isoniazid/rifampicininduced rats [13]. Isoniazid/rifampicin-induced nephrotoxicity was further confirmed by the recorded histological alterations including atrophy of glomerular tuft, dysplastic renal tubules and inflammatory cells infiltration, as we recently reported [13]. Concomitant administration of either dose of $R$. graveolens leaves extract significantly decreased circulating creatinine, urea and uric acid levels, and potentially attenuated the induced histological alterations in the kidney. Accordingly, we have recently demonstrated that $R$. graveolens at dose level of $50 \mathrm{mg} / \mathrm{kg}$ markedly decreased circulating kidney function markers and prevented histopathological alterations in diethylnitrosamine-induced nephrontoxicity in rats [20]. We have also demonstrated that at dose level of $100 \mathrm{mg} / \mathrm{kg}, R$. graveolens was able to decrease serum urea levels in ammonium chloride-induced hyperammonemic rats [19].

Isoniazid and rifampicin administration induced a significant increase in serum levels of the pro-inflammatory cytokine TNF-a which represents an important mediator of inflammatory tissue damage. Studies presented evidence that nephrotoxicants could provoke an inflammatory response leading to organ injury [12,34]. The significantly elevated TNF- $\alpha$ reflects the degree of inflammation. In this context, our previous studies demonstrated a marked increase in serum pro-inflammatory cytokines in anti-tuberculosis drugs administered rats $[9,13]$. In a dose-dependent manner, concurrent administration of $R$. graveolens leaves extract produced pronounced decline in serum TNF- $\alpha$, indicating its anti-inflammatory efficacy. These findings are in agreement with our recent study where we reported the ability of $R$. graveolens to decrease circulating levels of TNF- $\alpha$ in hyperammonemic rats [19].

The kidneys are vulnerable to damage caused by reactive oxygen species due to the abundant long chain polyunsaturated fatty acids in the composition of their membrane lipids [35]. Here, isoniazid/ rifampicin-induced rats showed marked elevation of the lipid peroxidation marker, MDA, and nitric oxide, revealing oxidative as well as nitrosative stress. Under oxidative stress conditions, reactive oxygen species induce DNA fragmentation, cellular injury, protein damage and lipid peroxidation [36,37]. In addition, isoniazid/ rifampicin-induced rats exhibited significantly declined renal GSH content which is a potent antioxidant forming S-conjugates with products of lipid peroxidation [38]. Furthermore, activity of the antioxidant enzymes SOD and GPx was declined in kidneys of the isoniazid/rifampicin-induced rats. These enzymes play an important role in protecting the body against the deleterious effects of reactive oxygen species [39]. Accordingly, we have demonstrated increased lipid peroxidation and declined antioxidant defenses in kidney of isoniazid/rifampicin-administered rats [13]. Concomitant treatment with $R$. graveolens leaves extract markedly decreased kidney lipid peroxidation and nitric oxide, and enhanced the antioxidant defenses, suggesting a potent free radical scavenging and antioxidant efficacies. We have previously showed the antioxidant and renoprotective effects of R. graveolens in hyperammonemic and diethylnitrosamineinduced rats $[19,20]$. Therefore, we assume that the protective mechanism of $R$. graveolens against isoniazid/rifampicin-induced nephrotoxicity is mediated partially through prevention of GSH decline and potentiation of the antioxidant enzymes.

In conclusion, the present investigation confers new information on the protective mechanism of $R$. graveolens leaves extract against anti-tuberculosis drug-induced nephrotoxicity. This renoprotective effect could be attributed to the ability of $R$. graveolens to attenuate inflammation, inhibit lipid peroxidation, prevent GSH decline and enhance the enzymatic antioxidant defenses.

\section{References}

1. Ferguson MA, Vaidya VS, Bonventre JV (2008) Biomarkers of nephrotoxic acute kidney injury. Toxicology 245: 182-193.

2. Finn W, Porter G (2003) Urinary biomarkers and nephrotoxicity. Clinical Nephrotoxins, 2nd ed. Kluwer Academic Publishers, Massachusetts 621-655.

3. Finlay S, Bray B, Lewington AJ, Hunter-Rowe CT, Banerjee A, et al. (2013) Identification of risk factors associated with acute kidney injury in patients admitted to acute medical units. Clin Med 13: 233-238.

4. Mehta RL, Pascual MT, Soroko S, Savage BR, Himmelfarb J, et al. (2004) Spectrum of acute renal failure in the intensive care unit: The PICARD experience. Kidney Int 66: 1613-1621.

5. Uchino S, Kellum JA, Bellomo R, Doig GS, Morimatsu H, et al. (2005) Acute renal failure in critically ill patients: A multinational, multicenter study. JAMA 294: 813-818.

6. Naughton CA (2008) Drug-induced nephrotoxicity. Am Fam Phys 78: 743750 .

7. Taber SS, Mueller BA (2006) Drug-associated renal dysfunction. Crit Care Clin 22: 357-374.

8. Kumar R, Shalimar, Bhatia V, Khanal S, Sreenivas V, et al. (2010) Antituberculosis therapy-induced acute liver failure: magnitude, profile, prognosis, and predictors of outcome. Hepatology 51: 1665-1674.

9. Mahmoud A M, Germoush MO, Soliman AS (2014) Berberine attenuates isoniazid-induced hepatotoxicity by modulating peroxisome proliferatoractivated receptor $\mathrm{\gamma}$, oxidative stress and inflammation. Int $\mathrm{J}$ Pharmacol 10 : 451-460.

10. Pal R, Vaiphei K, Sikander A, Singh K, Rana SV. (2006) Effect of garlic on isoniazid and rifampicin induced hepatic injury in rats. World J Gastroenterol 12: 636-639.

11. Lopez-Novoa JM, Quiros Y, Vicente L, Morales Al, Lopez-Hernandez FJ (2011) New insights into the mechanism of aminoglycoside nephrotoxicity: an integrative point of view. Kidney Int 79: 33-45.

12. Mahmoud AM, Galaly SR, Ahmed OM. (2014): Thymoquinone and curcumin attenuate gentamicin-induced renal oxidative stress, inflammation and apoptosis in rats. EXCLI J 13: 98-110.

13. Mahmoud AM, Morsy BM, Abdel-Hady DS, Samy RM (2015) Prunus armeniaca leaves extract protects against isoniazid and rifampicin induced 
nephrotoxicity through modulation of oxidative stress and inflammation. Int $\mathrm{J}$ Food Nutr Sci 2: 1-6.

14. Bhawna S, Kumar SU (2009) Hepatoprotective activity of some indigenous plants. Int J Pharm Tech 1: 1330-1334.

15. Miguel ES (2003) Rue in traditional Spain: frequency and distribution of its medicinal and symbolic applications. Econ Bot 57: 231-244.

16. Pathak S, Multani A, Banerji $P$, Banerji $P(2003)$ Ruta 6 selectively induces cell death in brain cancer cells but proliferation in normal peripheral blood lymphocytes: a novel treatment for human brain cancer. Int J Oncol 23: 975 982.

17. Preethi K, Kuttan G, Kuttan R (2006) Anti-tumour activity of Ruta graveolens extract. Asian Pac J Cancer Prev 7: 439-443.

18. Ahmed OM, Moneim AA, Yazid IA, Mahmoud AM (2010) Antihyperglycemic, antihyperlipidemic and antioxidant effects and the probable mechanisms of action of Ruta graveolens infusion and rutin in nicotinamide-streptozocin induced diabetic rats. Diabetol Croat 39: 15-35.

19. Mahmoud AM, Germoush MO, Soliman AS (2014) Ruta graveolens mitigates ammonium chloride-induced hyperammonemia by modulating antioxidant status and pro-inflammatory cytokines. Life Sci J 11: 269-275.

20. Mahmoud AM, Ahmed RR, Soliman HA, Salah M (2015) Ruta graveolens and its active constituent rutin protect against diethylnitrosamine-induced nephrotoxicity through modulation of oxidative stress. J App Pharm Sci 5: 16-21.

21. Young DS (1995) Effects of drugs on Clinical Lab. Tests, 4th ed AACC Press

22. Kaplan A (1984) Urea. Clin Chem The CV Mosby Co St Louis. Toronto Princeton, 1257-1260 and 437 and 418.

23. Fossati P, Prencipe L, Berti G (1980) Use of 3,5-dichloro-2 hydroxybenzenesulfonic acid/4-aminophenazone chromogenic system in direct enzymic assay of uric acid in serum and urine. Clin Chem 26: 227-231.

24. Preuss HG, Jarrell ST, Scheckenbach R, Lieberman S, Anderson RA (1998) Comparative effect of chromium vanadium and Gymnemasylvestre on sugarinduced blood pressure elevation in SHR. J Am Coll Nutr 17: 116-123.

25. Montgomery HAC, Dymock JF (1961) The determination of nitrite in water Analyst 86: 414-416.

26. Beutler E, Duron O, Kelly BM (1963) Improved method for the determination of blood glutathione. J Lab Clin Mid 61: 882-888.

27. Matkovics B, Szabo L, Varga IS (1998) Determination of enzyme activities in lipid peroxidation and glutathione pathways (in Hungarian). Laboratoriumi Diagnosztika 15: 248-249.

28. Marklund SL, Marklund G (1974) Involvement of the superoxide anion radical in the autoxidation of pyrogallol and a convenient assay for superoxide dismutase. Eur J Biochem 47: 469-474.

29. Rekha VVB, Santha T, Jawahar MS. (2005) Rifampicin induced renal toxicity during retreatment of patients with pulmonary tuberculosis. JAPI 53: 811-813.

30. Mahmoud AM (2014) Hesperidin protects against cyclophosphamide-induced hepatotoxicity by upregulation of PPARy and abrogation of oxidative stress and inflammation. Can J Physiol Pharmacol 92: 717-724.

31. Adebisi SA, Oluboyo PO, Okesina AB (2000) Effect of drug-induced hyperuricaemia on renal function in Nigerians with pulmonary tuberculosis. Afr J Med Med Sci 3-4:297-300.

32. Rached E, Hoffmann D, Blumbach K, Weber K, Dekant W, et al. (2008) Evaluation of putative biomarkers of nephrotoxicity after exposure to ochratoxin A in vivo and in vitro. Toxicol Sci 103: 371-381.

33. Hashmi N, Muhammad F, Javed I, Khan JA, Khan MZ, et al. (2013) Nephroprotective effects of Ficus religiosa linn (peepal plant) stem bark against isoniazid and rifampicin induced nephrotoxicity in albino rabbits. Pak Vet J 33: 330-334.

34. Araujo LP, Truzzi RR, Mendes GE, Luz MA, Burdmann EA, et al. (2012) Annexin A1 protein attenuates cyclosporine-induced renal hemodynamics changes and macrophage infiltration in rats. Inflamm Res 61: 189-196.

35. Ozbek E (2012) Induction of oxidative stress in kidney. Int J Nephrol 2012: 465897.

36. Mittal G, Brar AP, Soni G (2006) Impact of hypercholesterolemia on toxicity of Nnitrosodiethylamine:Biochemical andhistopathological effects. Pharmacol Rep 58:413-419.

37. Nencini C, Giorgi G, Micheli L (2007) Protective effect of silymarin on oxidative stress in rat brain. Phytomedicine 14: 129-135.

38. Laurent A, Perdu-Durand E, Alary J, Debrauwer L, Cravedi JP (2000) Metabolism of 4-hydroxynonenal, a cytotoxic product of lipid peroxidation in rat precision-cut liver slices. Toxicol Lett 114: 203-214.

39. Wei XJ, Hu TJ, Chen JR, Wei YY (2011) Inhibitory effect of carboxymethylpachymaran on cyclophosphamide-induced oxidative stress in mice. Int J Biol Macromol 49: 801-805.

Copyright: (C) 2016 Hussein OE, et al. This is an open-access article distributed under the terms of the Creative Commons Attribution License, which permits unrestricted use, distribution, and reproduction in any medium, provided the original author and source are credited. 